\title{
Initiation of Biphasic Insulin Aspart in a Patient Failing Basal Insulin Treatment
}

\author{
Janusz Gumprecht
}

Professor, Department of Internal Diseases, Diabetology and Nephrology, Medical University of Silesia

\begin{abstract}
This case illustrates insulin intensification from insulin glargine to biphasic insulin aspart 30 (BIAsp 30), reviews supporting clinical literature and discusses alternative therapeutic approaches. PL, a 56-year-old male with an eight-year history of type 2 diabetes, needed to intensify his insulin glargine treatment as he was not achieving appropriate blood glucose targets and recurrent hypoglycaemia limited further dose titration. With insulin glargine, his glycosylated haemoglobin $\left(\mathrm{HbA}_{1 \mathrm{c}}\right)$ was $7.8 \%$, his fasting plasma glucose (FPG) ranged from $7.2 \mathrm{mmol} / \mathrm{l}$ to $8.0 \mathrm{mmol} / \mathrm{l}$ and his postprandial glucose (PPG) ranged from $8.9 \mathrm{mmol} / \mathrm{l}$ to $10.6 \mathrm{mmol} / \mathrm{l}$, being especially high after dinner. At four months after the switch to BIAsp 30, his $\mathrm{HbA}_{1 \mathrm{c}}$ was $6.9 \%$ and his FPG and PPG levels were at goal. The patient had not experienced any hypoglycaemic episodes. By addressing both PPG and FPG, intensification with BIAsp 30 provided improved glycaemic control without the hypoglycaemia experienced with insulin glargine.
\end{abstract}

\section{Keywords}

Biphasic insulin aspart 30 (BIAsp 30), fasting plasma glucose (FPG), insulin, insulin glargine, postprandial glucose (PPG), type 2 diabetes

Disclosure: Janusz Gumprecht has participated in advisory boards and speakers' bureaux for Novo Nordisk.

Acknowledgements: Medical writing support was provided by Watermeadow Medical Ltd, funded by Novo Nordisk.

Received: 2 September 2011 Accepted: 7 September 2011 Citation: European Endocrinology, 2011;7(2):127-8 DOI:10.17925/EE.2011.07.02.127

Correspondence: Janusz Gumprecht, Department of Internal Diseases, Diabetology and Nephrology, Medical University of Silesia, Zabrze, Poland. E: jgumprecht@sum.edu.pl

Support: The publication of this article was funded by Novo Nordisk A/S, Denmark. The views and opinions expressed are those of the author and not necessarily those of Novo Nordisk A/S, Denmark.

Premix insulin analogues such as biphasic insulin aspart 30 (BIAsp 30) offer a convenient and simple way to intensify basal insulin therapy once the basal insulin is no longer able to control glycosylated haemoglobin $\left(\mathrm{HbA}_{1 \mathrm{c}}\right)$. Simple treatment algorithms are available for intensifying patients on once- or twice-daily basal insulin to BIAsp 30 twice daily, or for patients on once- or twice-daily BIAsp 30 who require twice- or three-times-daily BIAsp 30. ${ }^{1}$ By switching to BIAsp 30 twice daily, patients can provide coverage of their fasting plasma glucose (FPG) as well as postprandial glucose (PPG) at their two main meals and the addition of a third daily dose provides an easy way to intensify therapy further. ${ }^{1-3}$ In contrast, while basal insulins provide a simple way to initiate insulin, they fail to address PPG and therefore insulin intensification is more complicated. Patients either have to switch to a basal-bolus approach requiring two insulin devices, more invasive glucose monitoring and the difficulties of titrating both the basal and prandial components of therapy, or they can intensify therapy using a premix insulin. A basal-bolus approach may suit patients with very variable daily routines and mealtimes, those with good cognitive and physical function, those with a willingness to closely monitor their disease and those with a good support structure. Many patients, however, will prefer a simpler approach with a premix insulin that allows them to provide FPG and PPG control with a single insulin pen and an easy dose-titration algorithm. The following case report examines insulin intensification from insulin glargine to BIAsp 30 and reviews alternative treatment options.

\section{Case Report}

$\mathrm{PL}$ is a 56-year-old male with a body mass index (BMI) of $29 \mathrm{~kg} / \mathrm{m}^{2}$ and an eight-year history of type 2 diabetes. He has an active occupation but is minimally physically active in his free time and has irregular eating habits. He has non-proliferative diabetic retinopathy, concomitant hypertension and dyslipidaemia and, in addition to his diabetes medication, is receiving ramipril $10 \mathrm{mg} /$ day, simvastatin $40 \mathrm{mg} /$ day and acetylsalicylic acid (aspirin) 75 mg/day.

\section{Prior Diabetes Therapy}

The patient was receiving metformin 1,000 mg twice daily and glimepiride $4 \mathrm{mg} / \mathrm{day}$, which was not providing adequate control of his $\mathrm{HbA}_{1 \mathrm{c}}(8.8 \%, 73 \mathrm{mmol} / \mathrm{mol}), \mathrm{FPG}(8.9-10.6 \mathrm{mmol} / \mathrm{l})$ or PPG (8.9-12.2 mmol/I). Insulin initiation had been discussed three months earlier; however, the patient refused because of fear of injections and hypoglycaemia. It was decided to address the patient's concerns regarding insulin initiation by explaining the benefits of insulin and the need to control hyperglycaemia in order to minimise the risks of diabetes complications. In response to discussions about lifestyle modification, the patient indicated that he would try to increase his physical activity but that it would be impossible to change his irregular eating habits. He was prescribed once-daily insulin glargine. Following insulin initiation, metformin was continued but the patient was advised to discontinue glimepiride. The patient was advised to continue ramipril, simvastatin and acetylsalicylic acid. The starting dose was 14 units of 
Table 1: Follow-up After Initiation of Basal Insulin (Glargine, 0-4 Months) and Continuation of Biphasic Insulin (Biphasic Insulin Aspart 30, 0-4 Months)

\begin{tabular}{|c|c|c|c|c|c|c|}
\hline \multirow{2}{*}{ Case Parameter } & \multicolumn{6}{|c|}{ Month } \\
\hline & 0 & 2 & 4 & 0 & 2 & 4 \\
\hline & \multicolumn{3}{|c|}{ Insulin Glargine } & \multicolumn{3}{|c|}{ BIAsp 30} \\
\hline \multicolumn{7}{|l|}{ Total insulin dose: } \\
\hline U/day & 14 & 28 & 34 & 34 & 42 & 48 \\
\hline $\mathrm{U} / \mathrm{Kg}$ & 0.17 & 0.33 & 0.38 & 0.38 & 0.47 & 0.53 \\
\hline $\mathrm{HbA}_{1 \mathrm{C}}, \%$ & 8.8 & 8.2 & 7.8 & 7.8 & 7.1 & 6.9 \\
\hline FBG, mmol/l & $8.9-10.6$ & $7.4-8.2$ & $7.2-8.0$ & $7.2-8.0$ & $6.6-7.2$ & $<6.0$ \\
\hline 2-hour PPG, mmol/I & 8.9-12.2 & $9.0-10.8$ & $8.9-10.6$ & $8.9-10.6$ & $8.0-8.6$ & $<8.0$ \\
\hline Body weight, kg & 84 & 86 & 89 & 89 & 89 & 90 \\
\hline
\end{tabular}

BIAsp 30 = biphasic insulin aspart; $F B G=$ fasting blood glucose; $P P G=$ postprandial glucose.

insulin glargine administered in the evening to address his main problem of high FPG. He was asked to document all his self-monitored blood glucose (SMBG) results in a diary in order to self-titrate his insulin glargine every three to four days, based on pre-breakfast glucose, to achieve FPG levels of 5-7.2 mmol/l. At four months, the patient had increased his daily dose of insulin glargine to 34 units; however, recurrent hypoglycaemia limited further titration. The patient had also gained $5 \mathrm{~kg}$ in body weight. His $\mathrm{HbA}_{1 \mathrm{c}}$ had been reduced by approximately $1 \%$ to $7.8 \%$ (see Table 1). From his SMBG diary, his FPG ranged from $7.2 \mathrm{mmol} / \mathrm{l}$ to $8.0 \mathrm{mmol} / \mathrm{l}$; his PPG ranged from $8.9 \mathrm{mmol} / \mathrm{l}$ to $10.6 \mathrm{mmol} / \mathrm{l}$ (see Table 1) and was especially high after dinner.

\section{Intervention}

Recurrent hypoglycaemia limited titration options with once-daily insulin glargine. Therefore, the options for insulin intensification included a switch to a basal-bolus regimen by adding prandial insulin to main meals, or a switch to a premix insulin with breakfast and dinner. From a discussion of these options with the patient, it was determined that the premix insulin would be the most appropriate option given the patient's irregular eating habits, his wish for a simple regimen with only one injection device and twice- rather than the three-times-daily dosing with a basal-bolus approach. A biphasic insulin analogue was preferred over biphasic human insulin (BHI) due to its more physiological insulin profile, which has been shown to result in less nocturnal and major hypoglycaemia, and flexible mealtime administration.

The patient was advised to continue metformin, ramipril, simvastatin and acetylsalicylic acid, and to initiate BIAsp 30 with 20 units before dinner and 14 units before breakfast. He was advised to titrate his dosage based on pre-breakfast and pre-dinner results to achieve FPG and/or pre-dinner blood glucose $(B G)<6 \mathrm{mmol} / \mathrm{l}$. The necessity for making positive lifestyle changes was also reiterated. At the four-month follow-up, the patient had titrated his insulin dose up to 28 units of BIAsp 30 before dinner and 20 units of BIAsp 30 before breakfast (see Table 1). The patient's $\mathrm{HbA}_{1 c}$ was $6.9 \%$. His FPG and PPG levels were at goal (see Table 1). The patient had not experienced any hypoglycaemic episodes. He was advised to continue therapy and a follow-up visit was scheduled.

\section{Discussion}

This case demonstrates that intensifying treatment from once-daily basal insulin to twice-daily premix insulin analogue can result in improved glycaemic control. In this case, it was impossible to titrate the basal insulin any further due to recurrent hypoglycaemic episodes. The limitation with once-daily basal insulin regimens is that they fail to address PPG, which can be seen in this case as the patient's mean PPG remained between $8.9 \mathrm{mmol} / \mathrm{l}$ and $10.6 \mathrm{mmol} / \mathrm{l}$ following the switch from oral antidiabetic drug (OAD) combination to basal insulin. As endogenous insulin production declines, the failure to address PPG becomes an important issue, particularly at $\mathrm{HbA}_{1 \mathrm{c}}<7.3 \%$ where PPG has a larger impact than FPG. ${ }^{4}$ By intensifying treatment to BIAsp 30, both FPG and PPG were addressed and a marked improvement in $\mathrm{HbA}_{1 \mathrm{C}}$ from $7.8 \%$ to $6.9 \%$ was achieved. No episodes of hypoglycaemia were reported following the switch to BIAsp 30.

These results are in agreement with those from the IMPROVETM study, which was a multinational, open-label, non-randomised, 26-week observational study of over 52,000 individuals with type 2 diabetes. ${ }^{5-7}$ IMPROVE included patients whose physician had decided should be switched to BIAsp 30 according to their normal clinical practice. Of the overall IMPROVE population, $17 \%$ had received no prior pharmacological diabetes treatment, $65 \%$ were previously on OADs alone (64.5\%), and $18 \%$ were previously on insulin \pm OADS. Looking at the subset of patients previously on a basal insulin ( $n=748 ; 497$ on neutral protamine Hagedorn [NPH], 245 on insulin glargine, six receiving other combinations of insulin that were excluded from the analyses), BIAsp 30 significantly improved $\mathrm{HbA}_{1 \mathrm{c}}, \mathrm{FPG}$ and PPG while decreasing the rates of overall, major and minor hypoglycaemia from baseline. ' Looking at the 245 patients who switched from insulin glargine \pm OADs to BIAsp $30 \pm \mathrm{OADS}_{1} \mathrm{HbA}_{1 \mathrm{c}}$ was improved from $9.3 \%$ to $7.5 \%$, FBG was improved from $9.3 \mathrm{mmol} / \mathrm{l}$ to $6.9 \mathrm{mmol} / \mathrm{l}$ and PPG was reduced by $4.6 \mathrm{mmol} / \mathrm{l}$ post-breakfast, $3.8 \mathrm{mmol} / \mathrm{l}$ post-lunch and $3.1 \mathrm{mmol} / \mathrm{l}$ post-dinner, and was $<9 \mathrm{mmol} / \mathrm{l}$ following each meal $(p<0.0001$ for all measures).?

By addressing both PPG and FPG, intensification with BIAsp 30 provided improved glycaemic control without the problem hypoglycaemia experienced with insulin glargine.
1. Unnikrishnan AG, Tibaldi J, Hadley-Brown M, et al., Practical guidance on intensification of insulin therapy with BIAsp 30: a consensus statement, Int I Clin Pract, 2009;63:1571-7.

2. Yang WY, Ji QH, Zhu DL, et al., Thrice-daily biphasic insulin aspart 30 may be another therapeutic option for Chinese patients with type 2 diabetes inadequately controlled with oral antidiabetic agents, Chin Med I (Eng), 2009:122:1704-8.

3. Garber AJ, Wahlen J, Wahl T, et al., Attainment of glycaemic goals in type 2 diabetes with once-, twice-, or thrice-daily dosing with biphasic insulin aspart 70/30 (The 1-2-3 study),
Diabetes Obes Metab, 2006;8:58-66.

4. Monnier L, Colette C, Targeting prandial hyperglycemia: how important is it and how best to do this? Curr Diab Rep 2008;8:368-74.

5. Valensi P, Benroubi M, Borzi V, et al., IMPROVE Study Group Expert Panel. Initiating insulin therapy with, or switching existing insulin therapy to, biphasic insulin aspart 30/70 (Novo Mix 30) in routine care: sefety and effectiveness in patients with type 2 diabetes in care. safety and efectiveness in patients with type 2 diabetes in Shah S, Benroubi M, Borzi V, et al., IMPROVE Study Group Expert
Panel, Safety and effectiveness of biphasic insulin aspart 30/70 (NovoMix 30) when switching from human premix insulin in patients with type 2 diabetes: subgroup analysis from the 6-month IMPROVE observational study, Int I Clin Pract, 2009;63:574-82.

Gumprecht J, Benroubi M, Borzi V, et al., IMPROVE Study Group Expert Panel. Intensification to biphasic insulin aspart 30/70 (BIAsp 30, NovoMix 30) can improve glycaemic analysis of the IMPROVE observational study, Int I Clin Pract, 2009;63:966-72 


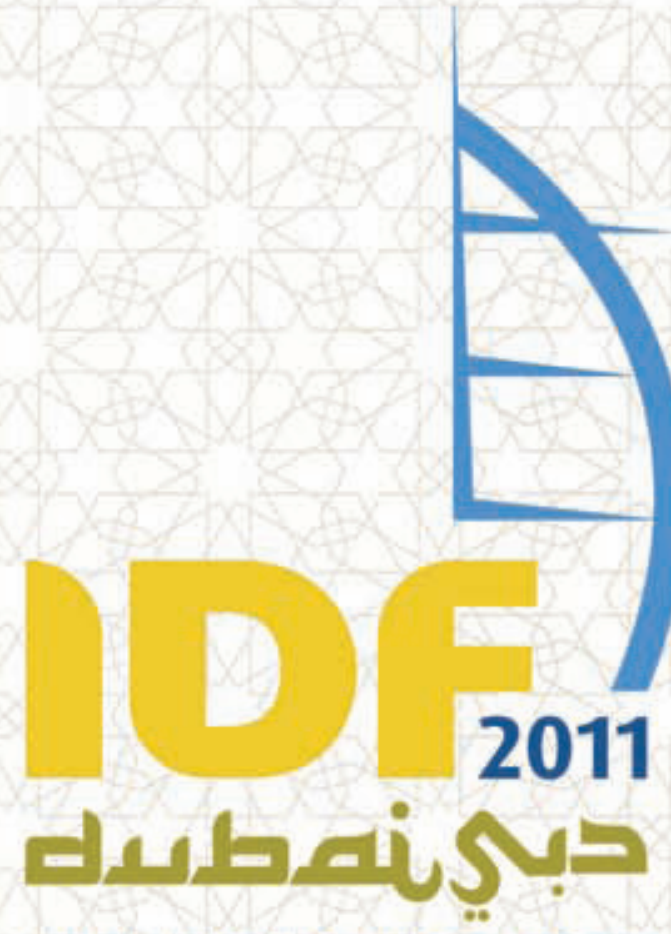

world diabetes congress

4-8 December 2011

Register early to benefit from reduced fees and preferential hotel rates. 